Methods All patients had either a single or double lumen external catheter (Hickman) or Portacath inserted. The choice of catheter for each patient is individualised. The Lothian Surgical Audit System, TRAK, iLAB and case notes were reviewed for patient demographics, surgical details of line insertion, line-associated complications and reasons for removal of line.

Results 140 patients underwent 213 line insertions, with 80 (57.1\%) patients experiencing a line-associated complication (total number of episodes $n=145)$. Proven infection was the most common complication (77 episodes, $53.1 \%$ ), followed by blockages (43 episodes, $29.7 \%$ ), dislodgement (12 episodes, 8.3\%), fracture (7 episodes, 4.8\%), kinking (2 episodes, 1.4\%), migration (1 episode, $0.7 \%$ ), extravasation ( 1 episode, $0.7 \%$ ), atelectasis ( 1 episode, $0.7 \%$ ) and skin breakdown over Portacath (1 episode, $0.7 \%$ ). The median (range) number of catheter days for single CVL was 309.5 days (range 9-1357 days) for Portacaths and 82.5 (15-218 days) for Hickman lines. The median catheter duration for double CVL was 198.5 (1-582) days and 112 (0-882) days for Portacaths and Hickman lines respectively. Single Hickman lines had the highest rate of premature removal (42.9\%), followed by double Hickman lines (42.6\%), double Portacaths $(35.7 \%)$ and single Portacaths $(22.9 \%)$. The presence of severe thrombocytopenia $\left(<50 \times 10^{\%} / \mathrm{L}\right)$ and severe neutropenia $\left(<0.5 \times 10^{9} / \mathrm{L}\right)$ at insertion were associated with higher rates of premature removal due to infection $(20.0 \%$ and $19.6 \%$ respectively), compared with CVL with platelet count $\geq 50 \times 10^{9} / \mathrm{L}$ and neutrophils $\geq 1.0 \times 10^{9} / \mathrm{L}(18.3 \%$ and $18.2 \%$ respectively).

Conclusion Single Portacaths are the longest surviving central venous lines. The presence of thrombocytopenia and/or neutropenia at the time of insertion may be associated with an increased risk of line sepsis and premature removal.

\section{G178 WHAT DO GPS AND BEREAVED PARENTS THINK ABOUT PAEDIATRIC ONCOLOGISTS AND PALLIATIVE CARE?}

doi:10.1136/archdischild-2013-304107.190

12 SJ Neilson, ${ }^{1} \mathrm{C}$ Clifford, ${ }^{3} \mathrm{~F}$ Gibson, ${ }^{1} \mathrm{SM}$ Greenfield. 'SChool of Health and Population Studies, University of Birmingham, Birmingham, UK; ${ }^{2}$ Paediatric Oncology Outreach Team, Birmingham Children's Hospital NHS Foundation Trust, Birmingham, UK; ${ }^{3}$ Department of Children's Nursing, London South Bank University, London, UK

Aim The aim of the study was to examine the experiences of bereaved parents and general practitioners (GPs) following the death of a child with cancer within the family home. This presentation focuses on one of the findings; the parent and GP views on the hospital consultants' involvement in the palliative care.

Design A community based qualitative study.

Setting West Midlands region, UK.

Participants Purposeful sample of 18 GPs and 11 bereaved families. The sample was drawn from the families and GPs of children who had been treated for cancer at a regional childhood cancer centre and who subsequently died within the family home.

Methods One-to-one semi-structured tape-recorded interviews were undertaken with GPs and bereaved parents following the death at home of a child with cancer. GPs were contacted three months after the death of the child and the parents at six months. Thematic analysis of the transcriptions was undertaken.

Findings Parents described feeling abandoned at the transition to palliation when management of care transferred to the GP. Families did not perceive a seamless service of medical care between hospital and community. Where offered consultant contact was valued by families and GPs. Text and email were used by families as a means of asking the consultant questions. The GPs lacked role clarity where the consultant continued involvement in the care.

Conclusions The transition to palliation and the transfer of care to community services needs to be sensitively and actively managed for the family and the GP. Medical care between tertiary and primary care should be seen as a continuum. Improving GP: consultant communication could aid role clarity, identify mechanisms for support and advice, and promote the active engagement of the GP in the care. Exploring opportunities for integrated consultant: GP working could maximise mutual learning and support and enhance care provision. The level, access and duration of ongoing contact between consultants and families/GPs require clarity.

\section{G179(P) LONG TERM FOLLOW-UP FOR PAEDIATRIC ONCOLOGY PATIENTS AT A PAEDIATRIC DEPARTMENT OF A GENERAL HOSPITAL}

doi:10.1136/archdischild-2013-304107.191

'SM Murphy, ${ }^{2} \mathrm{KM}$ Husselbee. 'Ninewells Hospital and Medical School, Dundee University, Dundee, UK; ${ }^{2}$ Tayside Children's Hospital, Ninewells Hospital, Dundee, UK

\section{Aims}

1. Establish how national Long Term Follow Up recommendations can be implemented locally in a paediatric department of a large general hospital.

2. Establish the number of patients who currently have an end of treatment summary in their notes.

3. Determine how many patients are attending appointments.

4. Identify if the appropriate patients are attending clinics.

Methods The medical notes for all patients appointed to attend the long term follow up clinic over the preceding two years were reviewed (93 patients).

It was noted whether each patient had an end of treatment summary present in their notes

Attendance at clinic over the past two years was noted.

Patients were assigned into different groups according to the 'Therapy-based recommended levels of follow-up'. ${ }^{1}$

\section{Abstract G179(P) Table 1}

\begin{tabular}{|c|c|c|c|c|}
\hline Level & Treatment & Follow up & Frequency & Examples \\
\hline 1 & $\begin{array}{l}\text { Surgery alone, Low risk } \\
\text { Chemotherapy }\end{array}$ & Postal or telephone & $1-2$ years & $\begin{array}{l}\text { Low risk Wilms' } \\
\text { LCH (single } \\
\text {-system) } \\
\text { GCH (Surgery only) }\end{array}$ \\
\hline 2 & $\begin{array}{l}\text { Chemotherapy, Low dose } \\
\text { cranial irradiation (<24 Gy) }\end{array}$ & $\begin{array}{l}\text { Nurse-led or primary } \\
\text { care }\end{array}$ & $1-2$ years & $\begin{array}{l}\text { Majority of patients } \\
\text { (eg ALL) }\end{array}$ \\
\hline 3 & $\begin{array}{l}\text { Radiotherapy (> } 24 \text { Gy) } \\
\text { Megatherapy }\end{array}$ & $\begin{array}{l}\text { Medically supervised } \\
\text { LFTU Clinic }\end{array}$ & Annually & $\begin{array}{l}\text { Brain tumours, post } \\
\text { BMT, Any stage } \\
4 \text { patients }\end{array}$ \\
\hline
\end{tabular}

\section{Results}

The majority (91\%) of patients did not have an end of treatment summary in their notes.

The majority of patients were in treatment 'level 2' (47\%). Those in levels $2 \& 3$ will require long term medically supervised follow-up (nurse led or GP if level 2).

Attendance at clinic was noted \& of those attending clinic, those with the best 'full time' attendance were those deemed to be 'level 2 ' patients. Followed by level 3 and 1 respectively.

Conclusion An 'End of Treatment Summary' should be implemented in the notes of all patients who have completed their treatment for childhood cancer.

Review current attendance of those deemed to be level 2 or 3 patients with the view to implementing a postal questionnaire in order to re-engage patients currently lost to follow-up.

\section{REFERENCE}

1. Wallace, W Blacklay, A Eiser, et al. Developing strategies for long term follow up of survivors of childhood cancer. BMJ 2001;323:271-4. 